
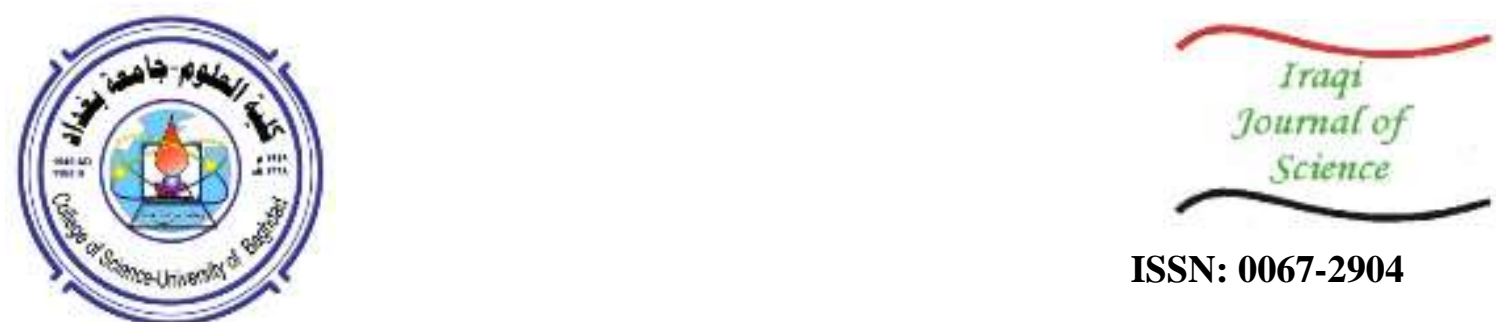

ISSN: 0067-2904

\title{
Studying the Effect of Laser Pump Pulse Energy and Delay Time on Conversion Efficiency of KTP
}

\author{
Raied K. Jamal ${ }^{1}$, Russul Khalil Rustum ${ }^{* 2}$ \\ ${ }^{1}$ Department of Physics, College of Science, University of Baghdad, Baghdad, Iraq \\ ${ }^{2}$ Ministry of Science and Technology, Baghdad, Iraq
}

Received: 19/7/ 2019

Accepted: 28/ 8/2019

\begin{abstract}
In this study, the effect of increasing pump pulse energy and delay time on the energy conversion efficiency of the Potassium Titanyl Phosphate (KTP) crystal at room temperature was investigated. It was found that the higher the pump pulse the greater the efficiency at a certain value of the delay time. Moreover, at the delay time $3.524 \mathrm{~ns}$, we found that the efficiency of the conversion of energy increases from 0.0112 to 0.0159 . We also observed that the lower delay time between the pump and the probe pulses leads to increase the rate of energy conversion efficiency of the KTP crystal, where the reaches up to 3 , which is higher than the value recorded in the absence of a pump pulse. The highest value of the rate of energy conversion efficiency recorded in this study was 0.0159 . This work was achieved at room temperature.
\end{abstract}

Keywords: KTP crystal, Pump Pulse energy, Delay time

$$
\begin{aligned}
& \text { دراسة تأثير طاقة نبضة المضخ الليزر وتأخير الوقت على كفاءة تحويل } \\
& \text { رائد كامل جمال 1، رسل خليل رستم2 } 2
\end{aligned}
$$

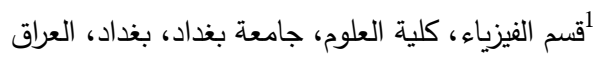

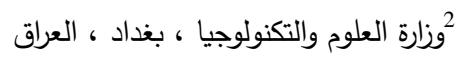

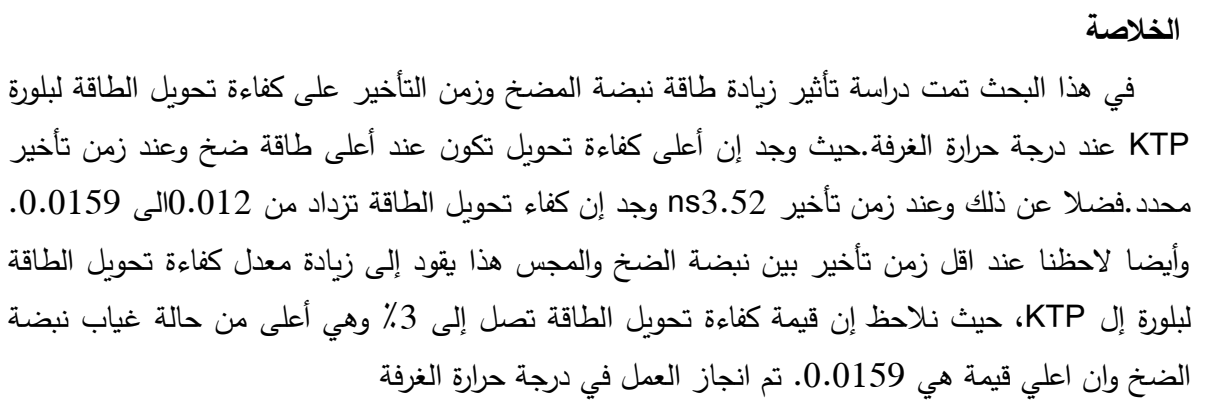

\section{Introduction}

In the material world, processes occur within a very fast period of time, such as in atomic and molecular vibrations, photon absorption and emission, electron-electron reconfiguration, etc. The above mentioned operations can occur within a time period of up to picoseconds. It is necessary to study and observe these very rapid processes in order to understand the dynamics of excitements

"Email: rusuiikhali1994@gmail.com 
within the material. There are several techniques for measuring high-speed processes, which must be the uncertainty, is smaller than the time scale of the operation, which are the limits of the femtosecond. The most prominent of these processes are the flow stop method [1] and flash analysis method [2].

The accuracy of time for rapid dynamic studies has been stabilized after the discovery of rapid optical diodes and stroboscopes, which have only time accuracy in the order of $10^{-10}$ seconds [3].

To overcome the subject of detector limitations, a new technique was developed which is fundamentally different from those previously used for measuring time. It is also used to measure the conversion efficiency of the optical intensity coming out of nonlinear material s[4-5]. The new technique is called the laser pump-probe technique [6], which records the laser pulse before and after passing through the non-linear material. The pump-probe laser technology is now one of the most basic technologies in the study of all spectra and has made scientific progress in many fields. There are many optical studies of KTP, such as those that investigated the non-Linear optical phase matching properties [7], the calculation of optimum phase match parameters for the biaxial crystals [8], the use of KTP as a harmonic generator for Nd:YAG laser [9], the efficient non-linear optical converters made of KTP crystals [10], and the efficient SHG in KTP crystals [11].

In this work, the effects of increasing the input power (pumping power) as well as the delay time on conversion efficiency were studied. Conversion efficiency is the ratio between the useful output of an energy conversion machine and the input, in energy terms. Generally, energy conversion efficiency is a dimensionless number between 0 and 1.0 , or $0 \%$ to $100 \%$. Efficiencies may not exceed $100 \%$.

\section{The theoretical part}

The electric field strength of the incident laser beam upon a KTP crystal can be represented by:

$$
\tilde{E}(t)=E e^{-i w t}+c . c
$$

The nonlinear polarization that is created in such a crystal is given according to

$$
\tilde{P}(t)=\chi^{(1)} \tilde{E}(t)+\chi^{(2)} \tilde{E}^{2}(t)+\chi^{(3)} \tilde{E}^{3}+\ldots
$$

$\chi^{(2)}$ represents the second-order susceptibility, where the second-order susceptibility can be written as follows:

$$
\chi^{(2)} \tilde{E}^{2}(t)=2 \chi^{(2)} E E^{*}+\left(\chi^{(2)} \tilde{E}^{2} \mathrm{e}^{-2 \omega t}+\text { c.c }\right)
$$

Through the equation above, it is noted that the second-order polarization consists of two parts: the first part at $\omega=$ zero and the second part at $2 \omega$. Using the wave equation, when light is in interaction with nonlinear materials, the second term of equation (3) leads to the generation of radiation with the second harmonic frequency, according to the equation below [12]:

$$
\nabla^{2} \widetilde{E}-\frac{n^{2}}{c^{2}} \frac{\partial^{2} \tilde{E}}{\partial t^{2}}=\frac{4 \pi}{c^{2}} \frac{\partial^{2} \tilde{P}^{N L}}{\partial t^{2}}
$$

Where $n$ and $c$ are the refractive index of the material and the velocity of light in the vacuum, respectively, where the polarization associated with the nonlinear response drives the electric field $E$. The equation above gives a fact when $\frac{\partial^{2} \tilde{P}^{N L}}{\partial t^{2}}$ is non-zero. It accelerates several times and generates accelerated loads of electromagnetic radiation. The second term in equation (3) is called the optical rectification.

The second harmonic generation process may be effective, where the incident beam light with frequency $\omega$ on the crystal will be converted to a double-frequency $2 \omega$ beam when appropriate conditions are available. The second harmonic generation is the degeneration case of three wave interactions, where two of the waves have equal frequencies $\omega_{1}=\omega_{2}=\omega$ and $\omega_{3}=2 \omega$. Therefore $E_{1}$ and $E_{2}$ are the electric fields of the same fundamental beam. Since $E_{1}=E_{2}=E_{\omega}$ and $E_{3}=E_{2 \omega}$, two coupled differential equations are [13]:

$$
\frac{d E_{\omega}}{d z}=i \omega \sqrt{\frac{\mu_{0}}{\varepsilon_{\omega}}} d_{i j k} E_{2 \omega} E_{\omega}{ }^{*} \exp (-i \Delta k z)
$$




$$
\frac{d E_{2 \omega}}{d z}=-2 i \omega(1 / 2) \sqrt{\frac{\mu_{0}}{\varepsilon_{2 \omega}}} d_{i j k} E_{\omega}{ }^{2} \exp (i \Delta k z)
$$

The factor of (1/2) has to be included in Eq. (7) to account for the degeneracy $\omega_{1}=\omega_{2}$. For efficient energy transfer it is necessary that the interacting waves remain in phase. With $k_{3}=k_{2 \omega}, k_{1}=k_{2}=k_{\omega}$ and $\Delta k=0$ in $\Delta k=2 k_{\omega}-k_{2 \omega}$, it is obtained that [13]:

$$
k_{2 \omega}=k_{\omega}+k_{\omega}
$$

Since $k_{\omega}=2 \pi n_{\omega} / \lambda_{0}$ and $k_{2 \omega}=4 \pi n_{2 \omega} / \lambda_{0}$, from the above condition Eq. (8) it follows that $n_{\omega}=n_{2 \omega}$. Therefore, the Phase Mismatch expressed by $\Delta k$ can be written in the case of frequency doubling as follows [13]:

$$
\Delta k=\frac{4 \pi}{\lambda_{0}}\left(n_{\omega}-n_{2 \omega}\right)
$$

Where $\lambda_{0}$ is the wavelength at the fundamental wave in vacuum. In this case, we can make the assumption that the fundamental beam is not depleted, and therefore $\frac{d E_{\omega}}{d z}=0$ in Eq. (6) and only Eq. (7) has to be considered. By observing the tensor properties of $d_{i j k}$, integration of Eq. (7) yields [13]:

$$
I_{2 \omega}=C^{2} L^{2} I_{\omega}{ }^{2} \frac{\sin ^{2}\left(\frac{\Delta k L}{2}\right)}{\left(\frac{\Delta k L}{2}\right)^{2}}
$$

Where $C=5 / 46 \frac{d_{e f f}}{\lambda_{0} n_{0}^{3 / 2}}, \mathrm{~L}$ is the length of the nonlinear crystal, $n_{0}$ is the refractive index at the fundamental wavelength $\lambda_{0}$, and $d_{e f f}$ is the effective nonlinear coefficient of the tensor $d_{i j k}$ for a particular nonlinear crystal.

$$
d_{i j k}=\varepsilon_{0} d_{e f f}
$$

Some authors include $\varepsilon_{0}$ in the nonlinear coefficient. In this case the unit of $d_{i j k}$ is $[A s / v 2]$ and $\mathrm{d}_{\mathrm{ijk}}[A s / v 2]=8 / 855 \times 10^{-12} d_{e f f}[\mathrm{pm} / \mathrm{v}] \cdot \lambda_{0}$ is measured in $\mu \mathrm{m}$, and the unit of $C$ is $\mathrm{GW}^{-1 / 2}$. In deriving Eq. (10) we used the conversion of electric field strength $E$ to intensity $I$ :

$$
I=n_{0} E^{2} / 2 z_{0}
$$

Where $z_{o}$ is the plane wave impedance in vacuum $z_{o}=\left(\mu_{0} / \varepsilon_{0}\right)^{1 / 2}=120 \pi[v / A]$. The conversion efficiency for frequency doubling follows from Eq. (10)

$$
\eta=C^{2} L^{2} I_{\omega} \operatorname{sinc}^{2}(\Delta k L / 2)
$$

Thus, the Second Harmonic Generation conversion efficiency in this work was expressed in the form of the above relation. Eq. (13), which is the desired equation upon which all the findings are based.

\section{Experimental work}

In order to study the effect of the input power factors and the delay time on conversion efficiency of KTP crystal, the pump-probe laser technique was used as shown in Figures-( 1 and 2). The Nd:YAG Q-Switching was used with a wavelength of $1064 \mu \mathrm{m}$, energy of $0-1000 \mathrm{~mJ}$ and a pulse width of 10 ns. In our research, the Potassium Titanyl Phosphate (KTiOPO4) (KTP) crystal was used. The KTP is widely used in both commercial and military lasers including laboratory and medical systems, range finders, lidar, optical communication and industrial systems. It has a large nonlinear optical coefficient, wide angular bandwidth and small walk-of angle. In addition, it has broad temperature and spectral bandwidth. The general properties of KTP are shown in Table-1 [11].

In general, the calculation of the energy conversion efficiency $(\eta)$ of KTP crystal is achieved by dividing the output energy $\left(E_{o}\right)$ on the input energy $\left(E_{i}\right)$, as shown in Figures- $(3$ and 4$)$. 


$$
\eta=\frac{\text { output energy }(E o)}{\text { input energy }(E i)}
$$

Figure-3 shows that the higher the input energy value the higher the conversion efficiency which had values that ranged $0.011-0.015 \%$.

When we return to Figure-1, to study the effects of the input power on the conversion efficiency of KTP, this requires the following several steps. The first step is to use a beam splitter that divides the laser pulse into two parts, namely a pump pulse and a probe pulse. After separating the two pulses, they reach the KTP crystal in two different paths by placing three mirrors in the pulse path of the probe. These mirrors are called M1, M2, and M3 and are separated by distances, as shown in table 2 (first row). The results demonstrated in table 2 indicate that the total path of the probe pulse is $126.5 \mathrm{~cm}$ while the path of the pump pulses is $25 \mathrm{~cm}$, so that the time delay between the two pulses is $3.524 \mathrm{~ns}$.

To study the effect of the change in the value of the input energy on the conversion efficiency $(\eta)$ of the KTP crystal, the value of the input energy on the crystal was changed as shown in Figure-5, which demonstrates that the higher the value of the input energy, the higher the value of the energy conversion efficiency $(\eta)$. The values are confined to 0.47-0.6\%. If we compare this ratio with the previous ratio, we observe an increase in the value of energy conversion efficiency $(\eta)$. The reason for this change in the system is a physical disorder that changes the state of balance. The cause of this disorder is the presence of the pump pulse, which takes a short and direct path to reach the crystalline KTP first. When the pulse of the pump first reaches the crystal, this pulse will interact with it in several ways, including energy and duration in order to excite the crystal. The simplest process that occurs in the crystal is the excitation of dipole inside. If the energy difference between the grand and the excited levels is equal to the pumping pulse energy, the crystal will absorb the photons that are incident on it, thus increasing the number of electrons at the excited level. When the pulse of the pump arrives and the crystalline state of excitement occurs, the pulse of the probe reaches a very short period of time. The delay between the pump and the probe pulse is controlled by changing the path length difference between the pump and the probe pulse, giving a delay that is described by:

$$
d T=d X / c
$$

where $\mathrm{c}$ is light speed and $d X$ is the path length difference. The optical mirrors M1, M2, and M3 can be mounted on translation stages to allow easy variation of path length difference (see table 2). The process of measuring the energy of the probe is performed using a detector after its interaction with the crystal, as shown in Figure-1.

Observing the modulation of the probe pulse after it has interacted with the KTP crystal is key to deducing the physical state of the KTP crystal as it decays back to an equilibrium state after the perturbation from the pump pulse. After the process of excitement in the KTP crystal as a result of the pump pulse, and after a very short time of the arrival of the pulse of the probe, where some of the electrons are still in the case of excitement, most of the pulse of the probe will be transmitted during the KTP crystal rather than being absorbed.

However, if many of the electrons that were previously excited by the pump pulse have already decayed by the time the probe pulse arrives, most of the probe pulse will be absorbed since many electrons reside again in the lower energy state. Thus, measuring the intensity modulation of the probe pulse as a function of delay will describe the population dynamics of the electron energy levels.

By using this technique, the duration of the laser pulse becomes very important; if some of the probe pulse was absorbed by an excitation in the KTP crystal, we know that this absorption had to occur during the time the pulse was present in the KTP crystal. Thus, if the pulse duration is very short, there is a very short time interval in which the absorption event could have taken place.

The effect of changing the pump pulse energy on KTP crystal on energy conversion efficiency at different delay times was examined, as shown in Figure- 6, which shows that the lower the delay time, the greater the conversion value of the energy to reach the efficiency of 3.

\section{Conclusion}

In the above, we could deduce that the efficiency of the conversion energy can be increased either by increasing the pump pulse energy or by reducing the delay time between two pulses using the pump-probe technique under the condition of temperature stabilization. 


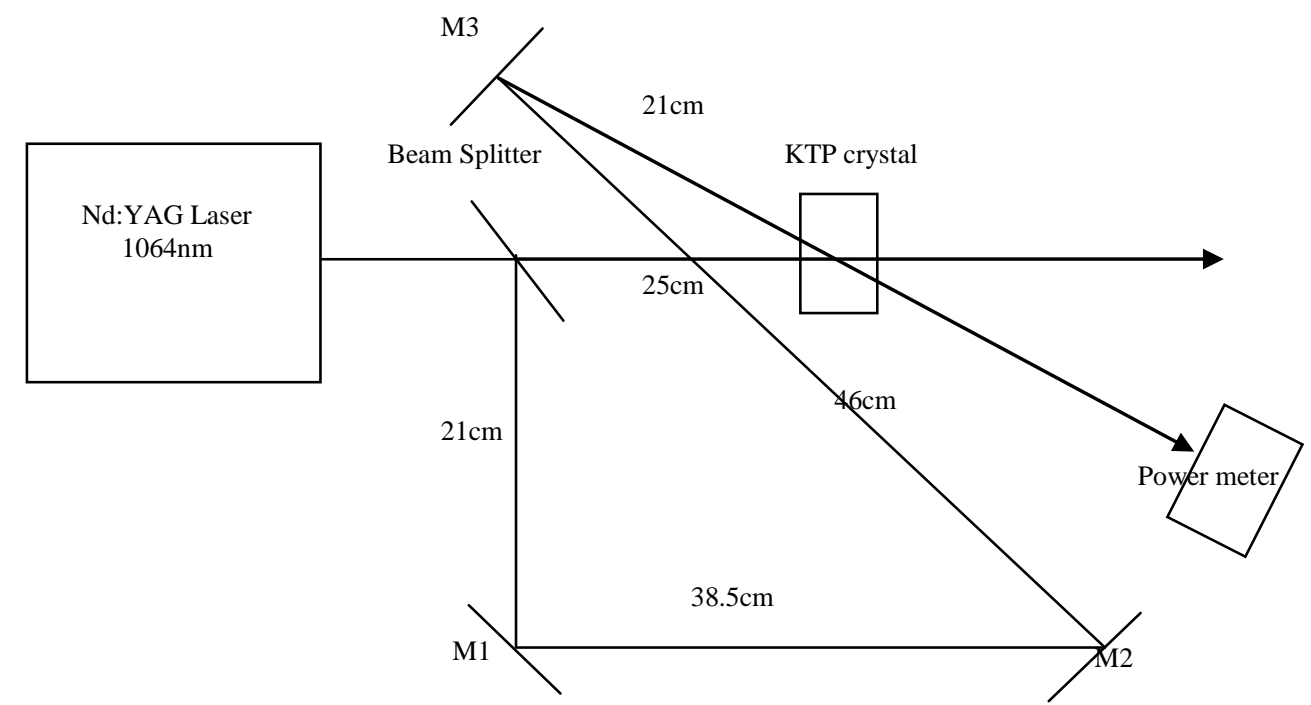

Figure 1-Pump-probe laser technique. The laser is split to pump and probe beam. The pump beam excites the sample. The probe beam interacts with the sample and then is detected. [3].

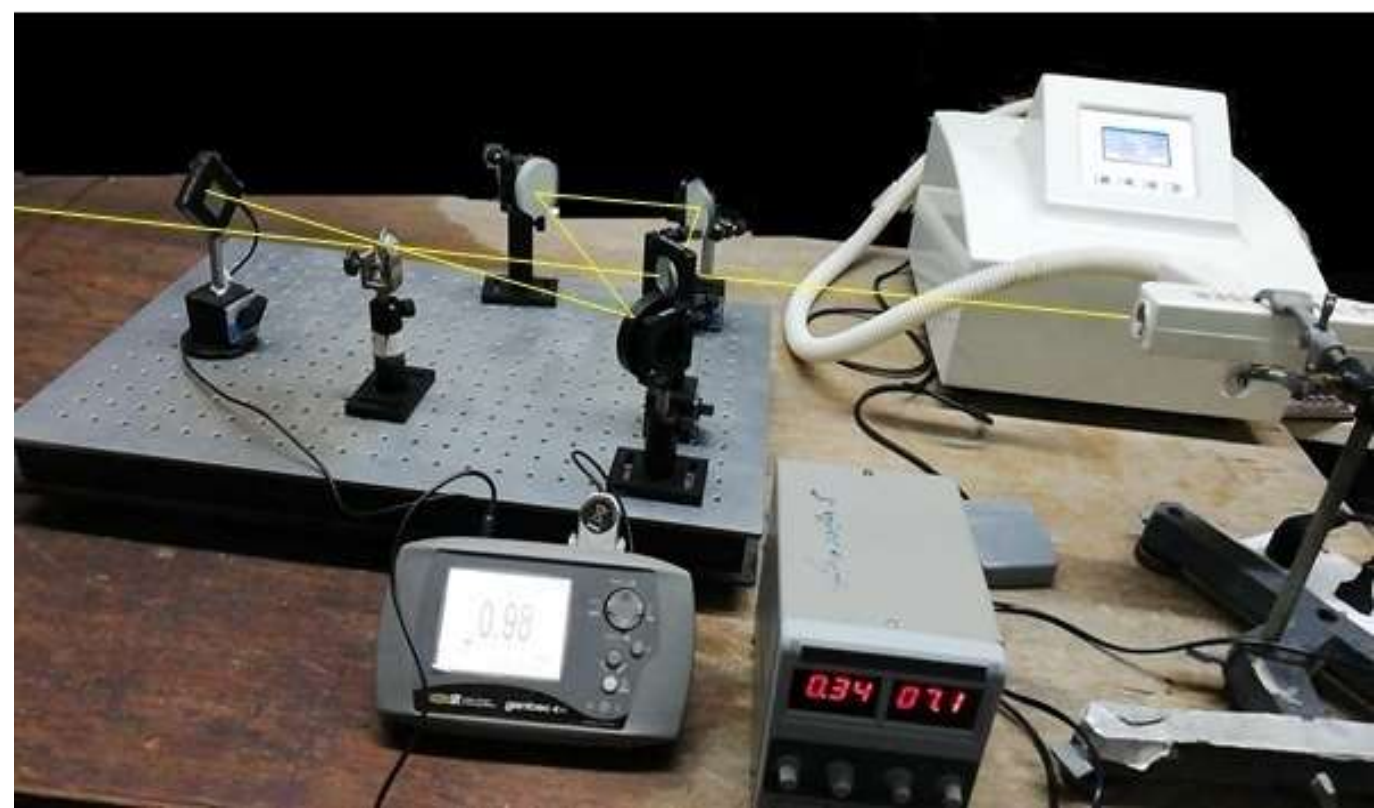

Figure 2- Pump-prop technique setup.

Table 1-The general properties of KTP crystal

\begin{tabular}{|c|c|c|c|c|c|c|c|c|c|}
\hline $\begin{array}{l}\text { Dimension } \\
\text { Tolerance }\end{array}$ & $\begin{array}{c}\text { Angle } \\
\text { Toleran } \\
\text { ce }\end{array}$ & $\begin{array}{c}\text { Parallelis } \\
\mathrm{m}\end{array}$ & $\begin{array}{l}\text { Perpendicula } \\
\text { rity }\end{array}$ & $\begin{array}{c}\text { Chamfe } \\
\mathrm{r}\end{array}$ & $\begin{array}{l}\text { Clear } \\
\text { apertur } \\
\mathrm{e}\end{array}$ & $\begin{array}{l}\text { Scratc } \\
\text { h and } \\
\text { Dig }\end{array}$ & $\begin{array}{l}\text { Surface } \\
\text { Flatnes } \\
\quad \mathrm{s}\end{array}$ & $\begin{array}{l}\text { Wave } \\
\text { front } \\
\text { distorti } \\
\text { on }\end{array}$ & $\begin{array}{c}\text { Damage } \\
\text { threshold } \\
\text { (AR coated) }\end{array}$ \\
\hline $\begin{array}{c}\mathrm{W} \times \mathrm{H}(+/- \\
0.1 \mathrm{~mm}) \\
\times \mathrm{L}(+0.5 /- \\
0.1 \mathrm{~mm})\end{array}$ & $\begin{array}{c}\Delta \theta \leq 0.2 \\
5^{\mathrm{o}} \\
\Delta \varphi \leq 0.2 \\
5^{\mathrm{o}}\end{array}$ & $\begin{array}{l}<20 \text { arc } \\
\text { seconds }\end{array}$ & $\begin{array}{c}<5 \text { arc } \\
\text { seconds }\end{array}$ & $\begin{array}{l}0.1 \mathrm{~mm} \\
\text { at } 45^{\circ}\end{array}$ & $90 \%$ & $10 / 5$ & $\begin{array}{l}\lambda / 8 \text { at } \\
633 \mathrm{~nm}\end{array}$ & $\begin{array}{l}\lambda / 8 \text { at } \\
633 \mathrm{~nm}\end{array}$ & $\begin{array}{c}>0.5 \mathrm{GW} / \mathrm{cm}^{2} \\
\text { TEMO, } \\
10 \mathrm{~ns}, 10 \mathrm{~Hz} \text { at } \\
1064 \mathrm{~nm} \\
>0.3 \mathrm{GW} / \mathrm{cm}^{2} \\
\text { TEMO, } \\
10 \mathrm{~ns}, 10 \mathrm{~Hz} \text { at } \\
532 \mathrm{~nm}\end{array}$ \\
\hline
\end{tabular}




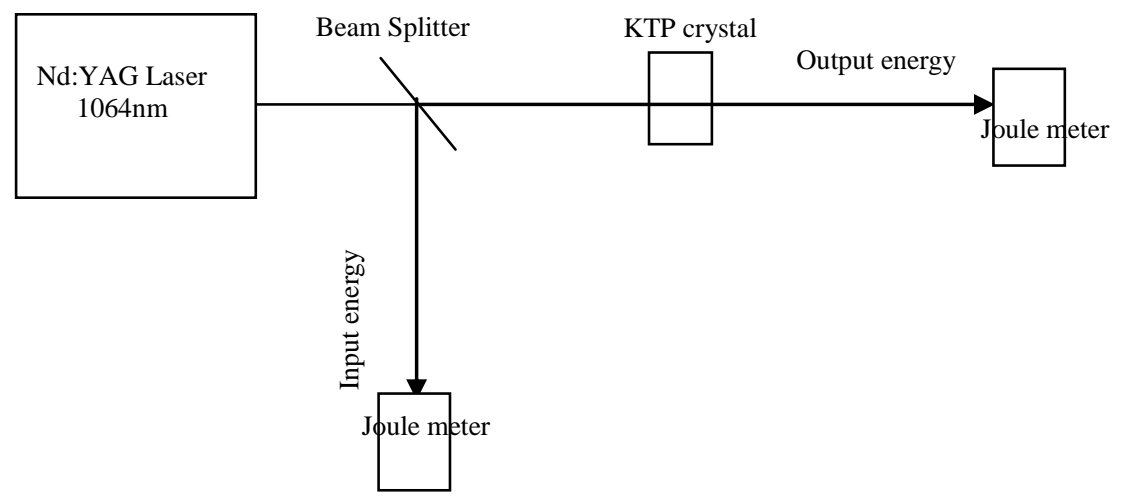

Figure 3-Energy conversion efficiency $(\mu)$ calculation system.

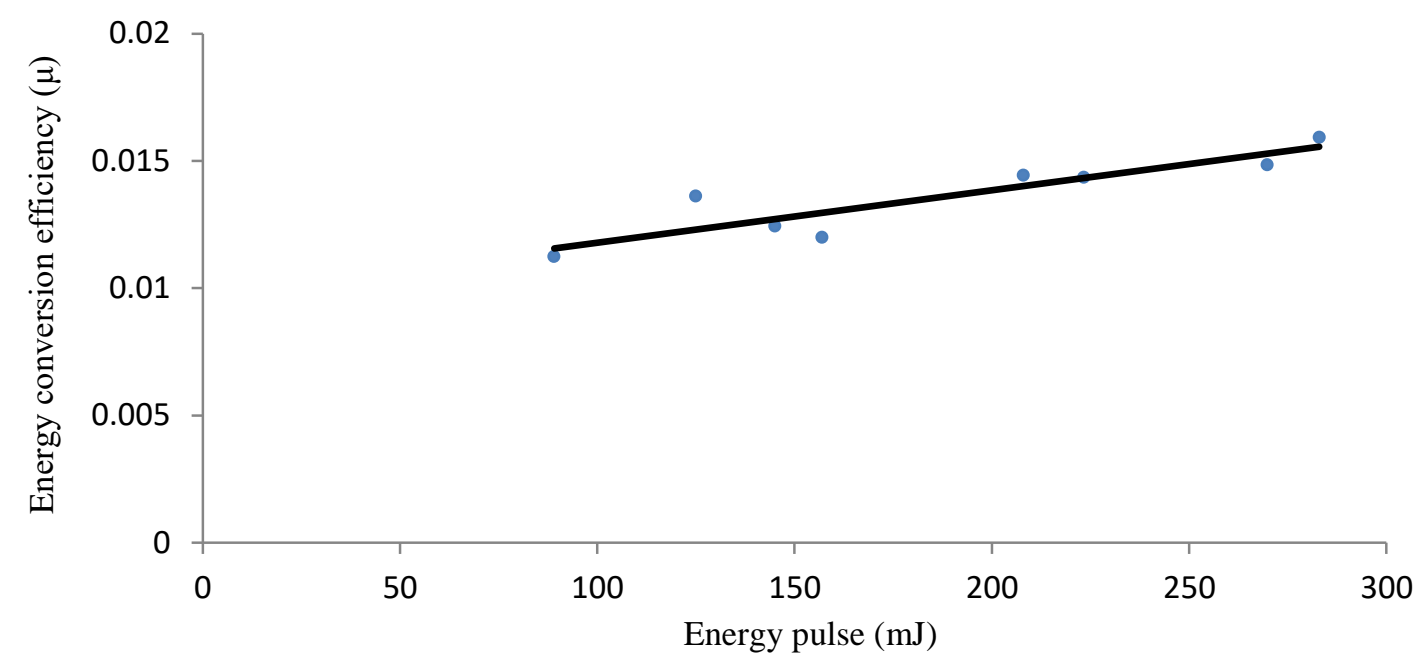

Figure 4-Energy conversion efficiency vs. input energy at 532nm wavelength and RT.

Table 2-The general dimension and parameters of pump-prop technique

\begin{tabular}{|c|c|c|c|c|c|c|}
\hline $\begin{array}{c}\text { Distance of } \\
\text { Beam splitter } \\
\text { to M1 } \\
(\mathrm{cm})\end{array}$ & $\begin{array}{l}\text { Distance } \\
\text { of M1 to } \\
\text { M2 (cm) }\end{array}$ & $\begin{array}{l}\text { Distance } \\
\text { of M2 to } \\
\text { M3 (cm) }\end{array}$ & $\begin{array}{l}\text { Distance of } \\
\text { M3 to KTP } \\
\text { crystal }(\mathrm{cm})\end{array}$ & $\begin{array}{c}\text { Total } \\
\text { distance of } \\
\text { probe pulse } \\
(\mathrm{cm})\end{array}$ & $\begin{array}{l}\text { Distance } \\
\text { of pump } \\
\text { pulse }(\mathrm{cm})\end{array}$ & $\begin{array}{l}\text { Delay time } \\
\text { between two } \\
\text { pulses } \\
\text { (ns) }\end{array}$ \\
\hline 21 & 38.5 & 46 & 21 & 126.5 & 25 & 3.524 \\
\hline 14.5 & 20 & 29 & 21 & 84.5 & 25 & 2.066 \\
\hline 5.5 & 7.5 & 14 & 21 & 48 & 25 & 0.798 \\
\hline
\end{tabular}




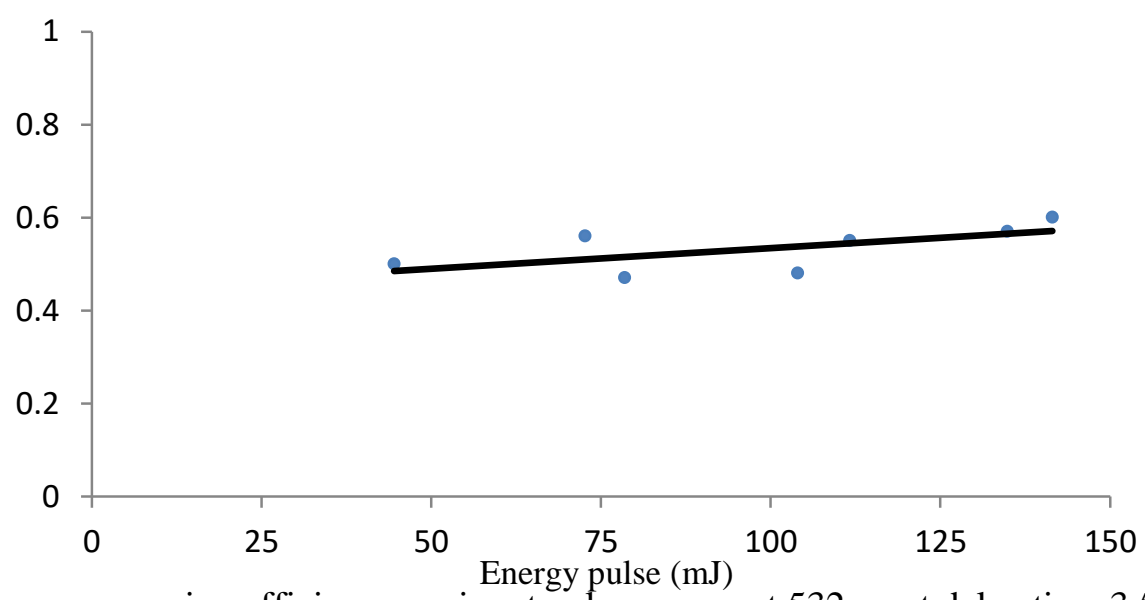

Figure 5-Energy conversion efficiency vs. input pulse energy at $532 \mathrm{~nm}$ at delay time $3.52 \mathrm{~ns}$ and RT.

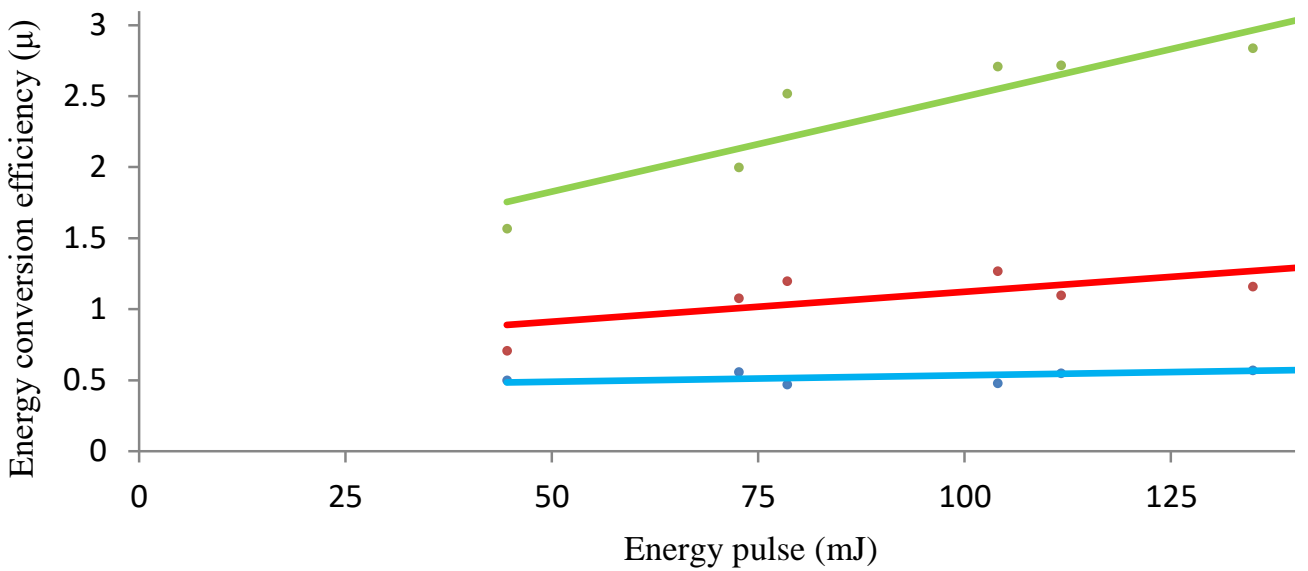

Figure 6-Energy conversion efficiency vs. input pulse energy at different delay times (blue line$3.524 \mathrm{~ns}$, red line-2.066ns, and green line-0.798ns).

\section{References}

1. Chance, B. 1940. "The accelerated flow method for rapid reactions." Journal of the Franklin Institute 229.6 (1940): 737-766.

2. Porter, G. "Flash photolysis and spectroscopy. A new method for the study of free radical Reactions, "Proceedings of the Royal Society of London. Series A. Mathematical and Physical Sciences 200.1061 (1950): 284-300.

3. Abramczyk, H. 2005. Introduction to Laser Spectroscopy.Amsterdam: Elsevier.

4. Krowne, C. M. and Zhang, Y. 2007. "Physics of Negative Refraction and Negative Index Materials", Optical and Electronic Aspects and Diversified Approaches. Springer-Verlag. pp. 331.

5. Zumsteg, R.F.C., Bierlein, J.D. and Gier, T.E. 1976. "KxRb1-xTiOPO4 A new non-linear optical material" J Appl. Phys. 47: 4980-4985.

6. Dong, Pu-Ting, and Ji-Xin Cheng, 2017. "Pump-Probe Microscopy: Theory, Instrumentation, and Applications." Spectroscopy 32(4): 2-11.

7. Liu, Y.S., Drafall, L., Dentz, D. and Belt, R. 1982. "Non-Linear Optical phase matching properties of KTP” G.E. Tech. Inform. Ser. Rep. 82 CRO16 General Electric, Schenectady, NY.

8. Yao, J.Q. and Fahlen, T.S. 1984. "Calculation of optimum phase match parameters for the biaxial crystal KTP" J. Appl. Phys. 55: 65-68.

9. Belt, R.F., Gashurov, G. and Liu, Y.S. 1985. "KTP as a harmonic generator for Nd:YAG laser", Laser Focus : 110- 122.

10. A.L. Aleksandrovskii, S.A., Akmanov, V.A., D'yakov, Zheludev, N.I. and Pryalkin, V.I. 1985. "Efficient Non-Linear optical converters made of KTP Crystals" Sov. J. Quantum Electron 15: 885- 886, 1985. 
11. Driscoll, T.A., Hoffman, H.J., Stone, R.E. and Perkins, P.E. 1986. "Efficient SHG in KTP crystals" J. Opt. Soc. Amer. 3: 683- 686.

12. Boyd, R. 2008. Nonlinear Optics (3rd ed.). Academic Press, Chap. 1 and 2.

13. Koechner, W. 2006. Solid-State Laser Engineering (Sixth ed.). Springer, 594-595. 